\title{
Statistical optimization of the synthesis of plant-derived fatty acid esters of TMP over homogeneous organometallic tin catalyst
}

\author{
Janusz Nowicki $^{{ }^{*} \text {, Jolanta Drabik }}{ }^{2}$, Dorota Stańczyk ${ }^{1}$, Jan Mosio-Mosiewski ${ }^{1}$, Piotr Woszczyński ${ }^{1}$ \\ ${ }^{1}$ Institute of Heavy Organic Synthesis "Blachownia”, Energetyków 9, PL47225 Kędzierzyn-Koźle, Poland \\ ${ }^{2}$ Institute for Sustainable Technologies - National Research Inst., K. Pulaskiego 6/10, PL26600 Radom, Poland \\ "Corresponding author: e-mail: nowicki.j@icso.com.pl
}

\begin{abstract}
A class of very important industrial-grade biolubricants was synthesized from plant-derived fatty acids (oleic and isostearic acid) by direct esterification of trimethylolpropane according to novel effective and high selective method using Sn bis(2-ethylhexanoate) as catalyst. Model transesterification reactions were performed with oleic and isostearic acids to optimize the reaction conditions to obtain maximum content of TMP triesters. Used specific homogeneous Sn catalyst allows to obtain TMP esters with very high content of triesters, above of $94 \mathrm{wt} \%$ without deep vacuum purifying distillation. Both TMP esters were evaluated for their physicochemical and tribological properties using ASTM standards. Both TMP esters exhibited high viscosity indexes and excellent low temperature properties.
\end{abstract}

Keywords: tin catalyst, trimethylolpropane esters, statistical optimization, tribology.

\section{INTRODUCTION}

Due to the higher environmental requirements and more restrictive regulations the development of biodegradable modern lubricants is observed $\mathrm{d}^{1,2}$. The modern lubricants should be more environmentally friendly and should by characterized by a higher level of performance and lower total life-cycle costs than the commonly used lubricants ${ }^{3}$. Synthetic esters biolubricants derived from renewable raw materials have been developed for applications in environmentally sensitive areas, such as forests, agriculture and aqueous areas due to their high biodegradability, low toxicity, and environmentally friendly nature. Synthetic esters biolubricants exhibit also good lubricity, excellent viscosity index, and lower volatility than common petroleum-based lubricants ${ }^{4,5}$. Most of the synthetic esters biolubricants are manufactured based on branched polyols, especially neopentyl glycol (NPG), trimethylolpropane (TMP) and pentaerythritol (PE) ${ }^{5-10}$. Among them TMP esters are especially important. Trimethylolpropane esters of sunflower and rapeseed oil-derived fatty acids can be used in the production of hydraulic fluids ${ }^{11,12}$. Trimethylolpropane esters of low viscosity and high temperature stability have long been used as lubricants for aircraft, and a method has been patented to produce esters of the high thermal stability required for lubricants used in high-performance jet turbine engines ${ }^{13}$. It has also been shown that mixtures containing trimethylolpropane esters having a sufficiently high viscosity as well as low pouring point for car engine oils can be prepared ${ }^{14,15}$.

Esters of higher fatty acid and higher polyols (neopentyl glycol, trimethylolpropane, pentaerythritol) are commercially available. Despite the important role of oleic acid esters of polyols, particularly TMP esters, in the market, the literature on the methods for their synthesis is very limited. Conventional methods of manufacturing trimethylolpropane esters of fatty acids are based on esterification processes conducted in the presence of strong acidic catalysts. The most commonly used are homogeneous sulfonic acids, such as sulfuric acid, methanesulfonic acid or p-toluenesulfonic acid ${ }^{16}$. The yield of the product does not usually exceed $95 \%$ and the crude ester require careful purification. Fatty acid esters of TMP can be also obtained by transesterification of fatty acid methyl esters (FAME) using conventional homogeneous basic catalyst ${ }^{17-21}$.

An alternative to the homogeneous catalysts are various types of heterogeneous catalysts such as acidic phosphates, metal oxides, synthetic silicates or acidic ion exchange resins ${ }^{22-28}$. Their main advantage is a very convenient separation from the post-synthesis mixture, but the great disadvantage of heterogeneous catalysts is the gradual loss of their activity, which is associated with the formation of a very troublesome waste. Acidic heterogeneous catalysts are also characterized by relatively low selectivity to the desired triester. In this context heterogeneous enzyme catalysts may be of interest ${ }^{4,29-31}$. Enzyme catalysts, despite the high yield and selectivity, are of lesser significance from the industrial point of view.

In the processes of manufacturing synthetic estertype biolubricants, particularly TMP fatty acid esters, organometallic Ti, Zr and Sn compounds may be used. They have been widely used as catalysts in synthetic polyester technologies. In the processes of esterification they exhibit high activity with relatively small amounts are required to effectively catalyze the reaction, generally not exceeding $1 \mathrm{wt} \%$. Thereby they not need to be removed from the post-synthesis mixtures. Method of the synthesis TMP oleate with the use of Sn oxalate as catalyst has been claimed German patent ${ }^{32}$. The described method allows to obtain a product characterized by good physicochemical and lubricant properties (viscosity and pour point), which can be acceptable for technical applications. Unfortunately, according to the described method it is possible to obtain ester characterized by low content of very important TMP triester (only $80 \mathrm{wt} \%$ ). In this paper the novel more effective and more selective method of the synthesis of TMP fatty acid esters using homogeneous Sn bis(2-ethylhexanoate) as catalyst was described (Scheme 1). The use of Sn catalyst allows to obtain product contains above $94 \mathrm{wt} \%$ of TMP triester. Developed method has been also optimized according to common adopted statistical procedure. 


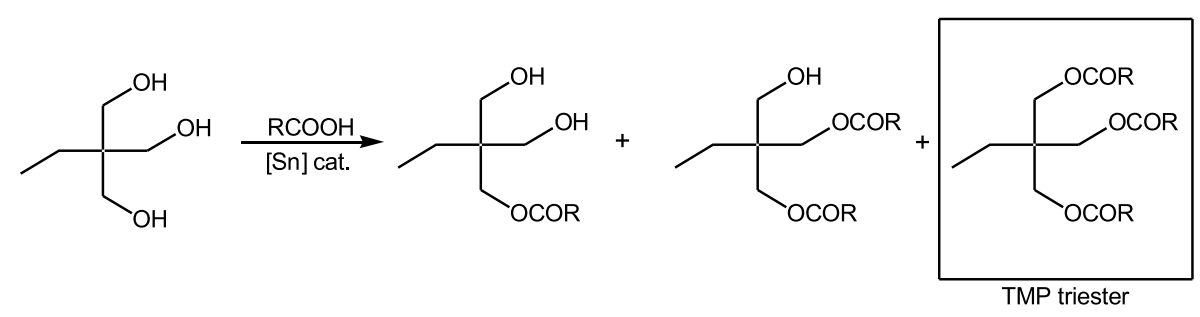

Scheme 1. Highly selective synthesis of trimethylolpropane fatty acid esters

\section{MATERIALS AND METHODS}

\section{Materials}

Tallow based oleic acid was purchased from Oleon as Radiacid 0212. Isostearic acid was purchased from Oleon as Radiacid 0908. This product contains ca. 83 wt $\%$ of branched and saturated acids $\mathrm{C} 16-\mathrm{C} 22$ and 16 wt $\%$ cyclic derivatives. Trimethylolpropane was purchased from Perstorp (Sweden). As catalysts was used a commercially available homogeneous $\mathrm{Sn}$ bis(2-ethylhexanoate) purchased as Fascat 2003 from PMC Organometallic.

\section{Analytical method}

Products were analyzed by gas chromatography with head-space system using HP 5890 Series II chromatograph equipped with flame ionization detector, capillary column, Ultra-high-2 (5HT), l = $15 \mathrm{~m}, \mathrm{~d}=0,32 \mathrm{~mm}$. All samples were transformed into silane derivatives with BSA (N,O-bis(trimethylsilyl)acetamide). Instrument settings: injector temp. $-360^{\circ} \mathrm{C}$, detector temp. $-380^{\circ} \mathrm{C}$. Temperature programming: initial isotherm $100^{\circ} \mathrm{C}-1 \mathrm{~min}$., $100-380^{\circ} \mathrm{C}-$ gradient $15^{\circ} \mathrm{C} / \mathrm{min}$., final isotherm $380^{\circ} \mathrm{C}-3 \mathrm{~min}$. Carrier gas: argon $-1.8 \mathrm{ml} / \mathrm{min}$. Quantitative interpretation of the results was performed by internal standardization for all components assuming a correction factor equal to 1 . The conversion rate of acid was calculated as the ratio between the amount of the acid consumed in the synthesis to a total amount of the acid used in the synthesis. Resultant ratios were then converted to percentages.

\section{Synthesis procedure}

A $200 \mathrm{~mL}$ glass reactor, equipped with a mechanical stirrer, an electronic temperature control system, a nitrogen purge glass capillary and a receiver to collect esterification water was charged with $180 \mathrm{~g}(0.6 \mathrm{~mol})$ of oleic or isostearic acid and required amount of trimethylolpropane (according to planned $\mathrm{COOH}: \mathrm{OH}$ molar ratio). The reactor was heated up to $150^{\circ} \mathrm{C}$ and then a proper amount of the catalyst was poured into the reactor. After stabilizing the flow of nitrogen, the temperature was raised to required temperature. The reaction mixture was stirred for 6 hours. During the synthesis, the esterification water was collected in the receiver. The crude ester was first washed with $5 \mathrm{wt} \%$ $\mathrm{K}_{3} \mathrm{PO}_{4}$ water solution and water to remove residual acidic impurities, and then it was dehydrated under slightly reduced pressure to remove residual water.

\section{Experimental design}

The optimization studies were conducted according to 3-level 3-factor plan of experiments based on common Box-Behnken statistical methodology, in order to determination the effects of the catalyst amount and process temperature on the triester content in postsynthesis mixtures ${ }^{33,34}$. Fifteen runs of experiments (three repetitive experiments) have been conducted for three levels of three independent variables: $\mathrm{X} 1-\mathrm{COOO}: \mathrm{OH}$ molar ratio; X2 - reaction temperature $\left({ }^{\circ} \mathrm{C}\right)$ and $\mathrm{X} 3-$ catalyst concentration (wt\%) to study the effect of the TMP triesters content (wt\%) in post-synthesis mixture (Y). Independent variables and their levels for TMP oleic acid ester are presented in Table S1 and for TMP isostearic acid in Table S3 (see Supporting Informations).

Other than for oleic acid molar ratios adopted for the calculation of the isostearic acid due to lower content of carboxyclic groups in the product. Acid number adopted for oleic acid was $200 \mathrm{mg} \mathrm{KOH} / \mathrm{g}$ and for isostearic acid $180 \mathrm{mg} \mathrm{KOH} / \mathrm{g}$.

\section{Statistical analysis}

A general linear interaction model (Eq. 1), which accounts for the independent parameters with their interaction effects was considered in this study.

$$
Y=\beta_{o}+\sum_{i=}^{n} \beta_{i} X_{i}+\sum_{i=1}^{n-1} \sum_{j=i+1}^{n} \beta_{i j} X_{i j}
$$

where $X_{i j}$ - the levels of the factors adopted in this under study $(i, j=1, \ldots, \mathrm{k})$

$Y$ - the predicted response of the process (TMP triesters contents, wt $\%$ ),

$n$ - the number of factors,

$\beta_{i}$ and $\beta_{i j}$ - the linear and interactive coefficients, respectively $(i, j=1, \ldots, \mathrm{k})$

The method of least squares was employed as certain values of the model parameters and analysis of variance (ANOVA) was applied to establish their statistical significance at a confidence level of $95 \%$. The optimum values of the selected explanatory variables $(\mathrm{Xi})$ were determined using STATGRAPHICS CENTURION 15 software for mathematical optimization and regression analysis. Microcal Origin 9.0 software was used for plot the response $3 \mathrm{D}$ plots and $2 \mathrm{D}$ surface plots.

\section{Physicochemical properties of polyol esters}

Kinematic viscosity measurements were made at 40 and $100^{\circ} \mathrm{C}$ using calibrated Ubbelohde Viscometer tubes. Viscosity and viscosity index (VI) were calculated using ASTM D 445 and ASTM D 2270 methods, respectively. All viscosity measurements were run in duplicate and the average value was reported. Pour points were determined according to standard ISO 3104. All runs were carried out in duplicate. Sample temperature was measured in $3^{\circ} \mathrm{C}$ increments at the top of the sample until it stopped pouring. Acid value was determined according to standard ISO 660:1996. Saponification value was determined according to standard ISO 3657:2013-10. 
Hydroxyl value was determined according to standard DIN 53240-1. Color of esters (Gardner) was determined on Hach-Lange Lico 100 colorimeter.

\section{Tribological properties of polyol esters}

Lubricating properties of the base oil and the influence of the modifiers on these properties were assessed using the T-02U universal machine. T-02U universal four-ball testing machine is intended for determination of antiwear (AW) properties of lubricants and engineering materials, as well as determination of the tendency of lubricants and engineering materials to produce surface fatigue failures (pitting). All the tests may be carried out at an elevated temperature. T-02U machine determines AW properties in accordance with the standards: ASTM D 2783, ASTM D 2596, ASTM D 4172, ASTM D 2266, IP 239.

The wear standardized measurements, the average wear scar diameter (d), was determined. The average wear scar diameter and limiting load of the wear, which characterizes the antiwear (AW) properties of the tested oils, were determined after the 3600-s runs at a constant rotational speed (1450 rpm) and constant load (392.4 N). Assessment of the antiseizure based on scuffing load (Pt) was determined according to the standardized methods. The scuffing load was determined after the $18 \mathrm{sec}$. runs at a constant rotational speed $(500 \mathrm{rpm})$ and a step-wise increasing load that were performed until seizure of the test balls was observed. Determining the value of scuffing load for steel-steel friction joint $(100 \mathrm{Cr} 6 / 100 \mathrm{Cr} 6)$ lubricated with investigated oils. Taken as a measure of resistance to scuffing load $\mathrm{Pt}$ at which a sharp increase in friction torque and limiting pressure of seizure poz characterized by the value of the loading force at which there has been a seizure of friction. The parameters values adopted in the tribological test are given in Table 1.

For tribological test steel balls $12.7 \mathrm{~mm}$ in diameter, with 60-65HRC hardness were used. The sample volume required for each test was $8 \pm 2 \mathrm{ml}$. The wear produced on the three stationary balls was measured under a calibrated microscope and reported as the WSD (wear scar diameter) or calculated wear.

\section{RESULTS AND DISCUSSION}

\section{Preliminary evaluation the synthesis of trimethylolpro- pane fatty acid esters}

Esterification reaction of polyols such as trimethylolpropane (TMP) and fatty acids in the presence of $\mathrm{Ti}$, $\mathrm{Zr}$, or Sn organometallic catalysts is similar to wellknown polyesterification processes leading to synthetic polyester resins. The esterification process catalyzed by homogeneous organometallic catalysts is characterized by relatively low requirements with respect to the amount of added catalyst and the temperature of $200-230^{\circ} \mathrm{C}$, which is related to required activation temperature for this type of catalysts. Our previous experience in the esterification process of fatty acids and polyols, particularly pentaerythritol, leading to determine the reaction conditions allow to obtain products with the desired composition ${ }^{35}$. The quality of synthesized TMP fatty acid ester depends on four key factors: reaction temperature, reagents molar ratio, amount of catalyst and reaction time. The use of organometallic tin catalyst in the synthesis of polyol esters was studied in more detail and we found that the high conversion of fatty acid $(>95 \%)$ is obtained after 4-5 hours of the synthesis ${ }^{35}$. In this study we have adopted 6 hours as effective reaction time and three other reaction parameters were further optimized. From several evaluated organometallic Lewis-type catalysts (Ti, $\mathrm{Zr}$ and $\mathrm{Sn}$ ) in studied process Sn bis(2-ethylhexanoate) was characterized by the highest activity and selectivity to desired products. The reaction conditions adopted for the synthesis of trimethylolpropane ester were analogous to the initial testing used in the esterification of pentaerythritol with oleic acid and isostearic (molar ratio $\mathrm{COOH}: \mathrm{OH}=1: 1$, reaction temperature $-220^{\circ} \mathrm{C}$, the amount of catalyst $-0.9 \mathrm{wt} \%$ ). After 6 hours the reaction yielded a product comprising $94.4 \mathrm{wt} \%$ of triester. Similar results were achieved also for isostearic acid ester. Content of diesters in crude product was below $5 \mathrm{wt} \%$ and monoesters $<1 \mathrm{wt} \%$. Content of unreacted fatty acids was $1.0-1.5 \mathrm{wt} \%$.

\section{Regression model analysis}

The data obtained from Box-Behnken experimental plan were analyzed by linear multiple regression using STATGRAPHICS 15 software. Due to the different assumptions in the construction of plans for the experiments for oleic acid and isostearic esters both processes have been described separately.

\section{Trimethylolpropane oleic acid ester.}

Tables S1 and S2 (Supporting Informations) showed designed matrix of experiments and responses of trimethylolpropane oleic acid triester contents in post-synthesis mixtures. The data obtained from Box-Behnken experiments were analysed by linear multiple regression using STATGRAPHIC 15 software. Based on this statistical model analysis the process was set for two factors: $\mathrm{COOH}$ : OH molar ratio (for oleic acid and tromethylolpropane respectively) (X1), reaction temperature (X2) and $\mathrm{COOH}$ : OH molar ratio (X1), amount of added catalyst (X3) was performed. Analysis of variance (ANOVA) was applied to establish the statistical significance of the model parameters. The significance of each parameter (coefficient) was determined by F-values and P-values (Table 2 and 3).

Table 1. The Values of parameters values of the tribological test adopted in this Study

\begin{tabular}{|l|c|c|c|}
\hline Parameter & $\mathrm{G}_{\mathrm{oz}}, \mathrm{Nmm}^{-2}$ & $\mathrm{P}_{\mathrm{t}}, \mathrm{N}$ & $\mathrm{p}_{\mathrm{oz}}, \mathrm{Nmm}^{-2}$ \\
\hline $\begin{array}{l}\text { Rotational velocity of } \\
\text { the upper ball }\end{array}$ & $1450 \mathrm{rpm}$ & $500 \mathrm{rpm}$ & $500 \mathrm{rpm}$ \\
\hline Time & $1 \mathrm{hour}$ & $18 \mathrm{~s}$ & $18 \mathrm{~s}$ \\
\hline Test temp., $\left[{ }^{\circ} \mathrm{C}\right]$ & $20 \pm 5$ & $20 \pm 5$ & $0 \pm 5$ \\
\hline Initial load of the test couple & $392.4 \mathrm{~N}$ & $0 \mathrm{~N}$ & $0 \mathrm{~N}$ \\
\hline Final load of the test couple & - & $4200 \mathrm{~N}$ & $7200 \mathrm{~N}$ \\
\hline Speed of load increase & - & Scuffing load $\mathrm{P}_{\mathrm{t}}$ & $409 \mathrm{~N} / \mathrm{s}$ \\
\hline Measurement & $\begin{array}{l}\text { Wear scar diameter, } \\
\text { Limiting load wear, } \mathrm{G}_{\mathrm{oz}}\end{array}$ & $\begin{array}{c}\text { Scar diameter, } \\
\text { Limiting seizure pressure } \mathrm{p}_{\mathrm{oz}}\end{array}$ \\
\hline
\end{tabular}


Table 2. Significance of regression parameters for TMP oleate synthesis $\left(X_{1}\right.$ i $\left.X_{2}\right)$

\begin{tabular}{|l|c|c|c|c|c|c|}
\hline Source & Sum of Squares & D.f. & Mean Square & $F$-Ratio & $P$-Value & Degree of significance \\
\hline $\mathrm{A}: \mathrm{X} 1$ & 22.4832 & 1 & 22.4832 & 88.00 & 0.0000 & high significant \\
\hline $\mathrm{B}: \mathrm{X} 2$ & 0.00274087 & 1 & 0.00274087 & 0.01 & 0.9198 & not significant \\
\hline $\mathrm{AA}$ & 1.68335 & 1 & 1.68335 & 6.59 & 0.0303 & possibly significant \\
\hline $\mathrm{AB}$ & 1.01937 & 1 & 1.01937 & 3.99 & 0.0769 & not significant \\
\hline $\mathrm{BB}$ & 1.12204 & 1 & 1.12204 & 4.39 & 0.0656 & not significant \\
\hline Total error & 2.29934 & 9 & 0.255482 & & & $\mathrm{R}^{2}=0.9377 ; \mathrm{R}^{2}$ (adjusted for D.f.) $=0.9031$ \\
\hline Total (corr.) & 36.916 & 14 & \multicolumn{5}{|l|}{} \\
\hline
\end{tabular}

Table 3. Significance of regression parameters for TMP oleate synthesis $\left(X_{1}\right.$ i $\left.X_{3}\right)$

\begin{tabular}{|l|c|c|c|c|c|c|}
\hline Source & Sum of Squares & D.f. & Mean Square & F-Ratio & P-Value & Degree of significance \\
\hline $\mathrm{A}: \mathrm{X} 1$ & 21.0021 & 1 & 21.0021 & 87.94 & 0.0000 & high significant \\
\hline $\mathrm{B}: \mathrm{X} 3$ & 0.284269 & 1 & 0.284269 & 1.19 & 0.3036 & not significant \\
\hline $\mathrm{AA}$ & 1.63699 & 1 & 1.63699 & 6.85 & 0.0279 & possibly significant \\
\hline $\mathrm{AB}$ & 1.12859 & 1 & 1.12859 & 4.73 & 0.0577 & not significant \\
\hline BB & 1.42936 & 1 & 1.42936 & 5.99 & 0.0570 & not significant \\
\hline Total error & 2.1493 & 9 & 0.238811 & & & \\
\hline Total (corr.) & 36.916 & 14 & \multicolumn{5}{|l|}{$\mathrm{R}^{2}=0.9417 ; \mathrm{R}^{2}$ (adjusted for D.f.) $=0.9094$} \\
\hline
\end{tabular}

The larger magnitude of the by F-values and smaller P-values $(<0.01)$ prove that, the corresponding coefficient is more significant. The T-test was used to determine the significance of the regression coefficients of variables, and P-value was the indicator of the significance of the statistical test, whose value below 0.001 means the variable is very significant and almost (probably) significant below 0.05 . It was noticed that the $\mathrm{COOH}: \mathrm{OH}$ molar ratio is highly significant followed the esterification temperature and catalyst amount.

To test the fit of the model, the determination coefficients R2 were evaluated. In case of X1 and X2 as function of $\mathrm{Y}$ the value of $\mathrm{R} 2=0.9377$. This indicates that the model could explain $93.77 \%$ of variability. That is only $6.23 \%$ of total variation are not explained by the model, which ensures the high compatibility of fit and confirming the adequacy of the adopted regression model. In case of X1 and X3 as function of $\mathrm{Y}$ the value of $\mathrm{R} 2=0.9417$. This indicates that the model could explain $94.17 \%$ of variability and also ensures the high compatibility of fit and confirming the adequacy of the adopted regression model

Based on the statistical analysis described above, it can be concluded that the adopted model is characterized by a very good degree of fit. The parameter describing the degree of fit of the model to experimental results reached $88.8 \%$. For most processes the value of this index $>85 \%$ is considered to be satisfactory. The re- sults in Tables 3 and 4 also indicate, as expected, that on the value of the parameter a function of response $Y$ (content triesters reaction mixtures), the strongest effect has $\mathrm{COOH}: \mathrm{OH}$ molar ratio.

\section{Trimethylolpropane isostearic acid ester.}

Tables S3 and S4 (Supporting Informations) showed designed matrix of experiments and responses of trimethylolpropane isostearic acid ester contents in postsynthesis mixtures.

Analogously to trimethylolpropane oleate the analysis of variance (ANOVA) was applied to establish the statistical significance of the model parameters. The significance of each parameter (coefficient) was determined by F-values and P-values (Table 4 and 5).

The T-test was used to determine the significance of the regression coefficients of variables, and P-value was the indicator of the significance of the statistical test, whose value below 0.001 means the variable is very significant and almost (probably) significant below 0.05 . It was noticed that in the synthesis of trimethylolpropane isostearate the $\mathrm{COOH}: \mathrm{OH}$ molar ratio is also highly significant followed the esterification temperature and catalyst amount. To test the fit of the model, the determination coefficients $\mathrm{R} 2$ were evaluated. In case of $\mathrm{X} 1$ and $\mathrm{X} 2$ as function of $\mathrm{Y}$ the value of $\mathrm{R} 2=0.8834$. This indicates that the model could explain $88.34 \%$ of variability. That is only $11.66 \%$ of total variation are not

Table 4. Significance of regression parameters for TMP isostearate synthesis $\left(X_{1}\right.$ i $\left.X_{2}\right)$

\begin{tabular}{|l|c|c|c|c|c|c|}
\hline Source & Sum of Squares & D.f. & Mean Square & F-Ratio & $P$-Value & Degree of significance \\
\hline A:X1 & 29.861 & 1 & 29.861 & 57.51 & 0.0000 & high significant \\
\hline B:X2 & 4.5586 & 1 & 4.5586 & 8.78 & 0.0159 & possibly significant \\
\hline AA & 0.319214 & 1 & 0.319214 & 0.61 & 0.4531 & not significant \\
\hline AB & 0.0151789 & 1 & 0.0151789 & 0.03 & 0.8680 & not significant \\
\hline BB & 0.18101 & 1 & 0.18101 & 0.35 & 0.5694 & not significant \\
\hline Total error & 4.67274 & 9 & 0.519193 & & $\mathrm{R}^{2}=0.8834 ; \mathrm{R}^{2}$ (adjusted for D.f.) $=0.8186$ \\
\hline Total (corr.) & 40.064 & 14 & \multicolumn{4}{l}{} \\
\hline
\end{tabular}

Table 5. Significance of regression parameters for TMP isosterarate synthesis $\left(X_{1}\right.$ i $\left.X_{3}\right)$

\begin{tabular}{|l|c|c|c|c|c|c|}
\hline Source & Sum of Squares & D.f. & Mean Square & F-Ratio & P-Value & Degree of significance \\
\hline A:X1 & 32.7772 & 1 & 32.7772 & 68.74 & 0.0000 & high significant \\
\hline B:X3 & 5.5364 & 1 & 5.5364 & 11.61 & 0.0093 & possibly significant \\
\hline AA & 0.303876 & 1 & 0.303876 & 0.64 & 0.4477 & not significant \\
\hline AB & 0.684968 & 1 & 0.684968 & 1.44 & 0.2650 & not significant \\
\hline BB & 1.34768 & 1 & 1.34768 & 2.83 & 0.1312 & not significant \\
\hline Total error & 3.81446 & 8 & 0.476807 & & $\mathrm{R}^{2}=0.9048 ; \mathrm{R}^{2}$ (adjusted for D.f.) $=0.8453$ \\
\hline Total (corr.) & 40.0636 & 13 & \multicolumn{5}{|l|}{}
\end{tabular}


explained by the model, which ensures the high compatibility of fit and confirming the adequacy of the adopted regression model. In case of X1 and X3 as function of $\mathrm{Y}$ the value of $\mathrm{R} 2=0.9048$ This indicates that the model could explain $90.48 \%$ of variability and also ensures the high compatibility of fit and confirming the adequacy of the adopted regression model.

\section{Effect of reaction parameters on TMP oleic acid ester synthesis}

The 3D plots and 2D contout plots were developed with trimethylolpropane triester contents in post-synthesis mixtures. This parameter of crude trimethylolpropane fatty acid esters is crucial for most of application properties, especially lubricant properties and pour point.

Figures $1 \mathrm{~A}$ and $2 \mathrm{~A}$ show the effect of $\mathrm{COOH}: \mathrm{OH}$ molar ratio and reaction temperature on TMP trioleate content in post-synthesis mixture formed in esterification reaction of oleic acid with trimethylolpropane catalysed by $\mathrm{Sn}$ di(2-ethylhexanoate) at a resident reaction time of $6 \mathrm{hr}$. The TMP trioleate content increased as the $\mathrm{COOH}$ : OH molar ratio increased to close to equimolar. Figures $1 \mathrm{~B}$ and $2 \mathrm{~B}$ show the effect of $\mathrm{COOH}: \mathrm{OH}$ molar ratio and amount of added catalyst on TMP trioleate content in post-synthesis mixture. The TMP trioleate content increased also as the reaction temperature increased from 210 to $230^{\circ} \mathrm{C}$. The maximum of TMP trioleate content $(94.8 \mathrm{wt} \%)$ can by obtained for the molar ratio from $0.99: 1$, reaction temperature $220-230^{\circ} \mathrm{C}$. A similar effect was also observed in effect of $\mathrm{COOH}: \mathrm{OH}$ molar ratio and amount of added catalyst. The maximum of TMP trioleate content can by obtained for the molar ratio from $0.98: 1$ to $0.99: 1$ and amount of added catalyst from 0.8 to $0.9 \mathrm{wt} \%$. (see Figure $1 \mathrm{~B}$ and $2 \mathrm{~B}$ ).

This study did not evaluate the effect of reaction time on the TMP triester content in post-synthesis mixtures. From our preliminary studies on the esterification of polyols with fatty acids shows, that eswterification reaction catalysed by $\mathrm{Sn}$, Ti and $\mathrm{Sn}$ organocatalysts was only slightly influenced by residence reaction time at the studied levels of reaction variables ${ }^{35}$. The main driving force of this reaction is associated with two other process parameters: resistant rotation speed (350 rpm and N2 stream at constant level).

According to the adopted model, the estimated optimum conditions for esterification of trimethylolpropane
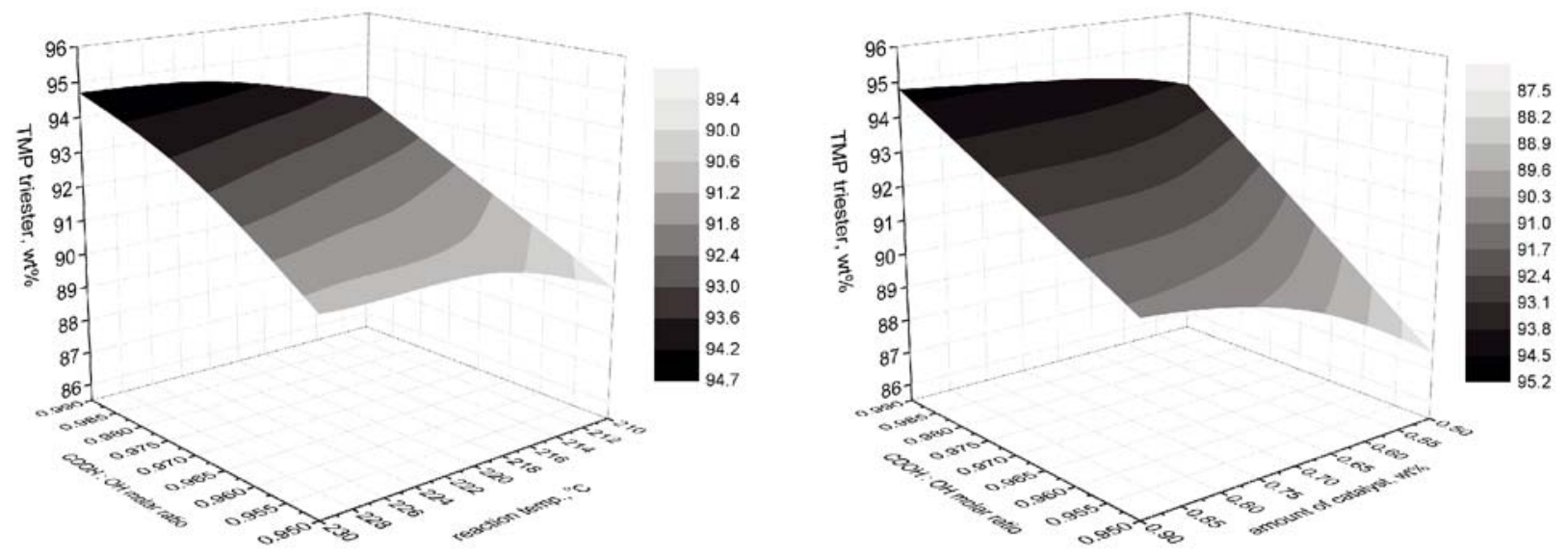

Figure 1. 3D surface plots for the trimethylolpropane trioleate content in post-synthesis mixtures. Change variables were (A) $\mathrm{COOH}: \mathrm{OH}$ molar ratio and reaction temperature (reaction time $-6 \mathrm{hr}$; catalyst $-0.7 \mathrm{wt} \%$ ), (B) $\mathrm{COOH}:$ molar ratio and amount of catalyst (reaction time $-6 \mathrm{hr}$; reaction temperature $-220^{\circ} \mathrm{C}$ )
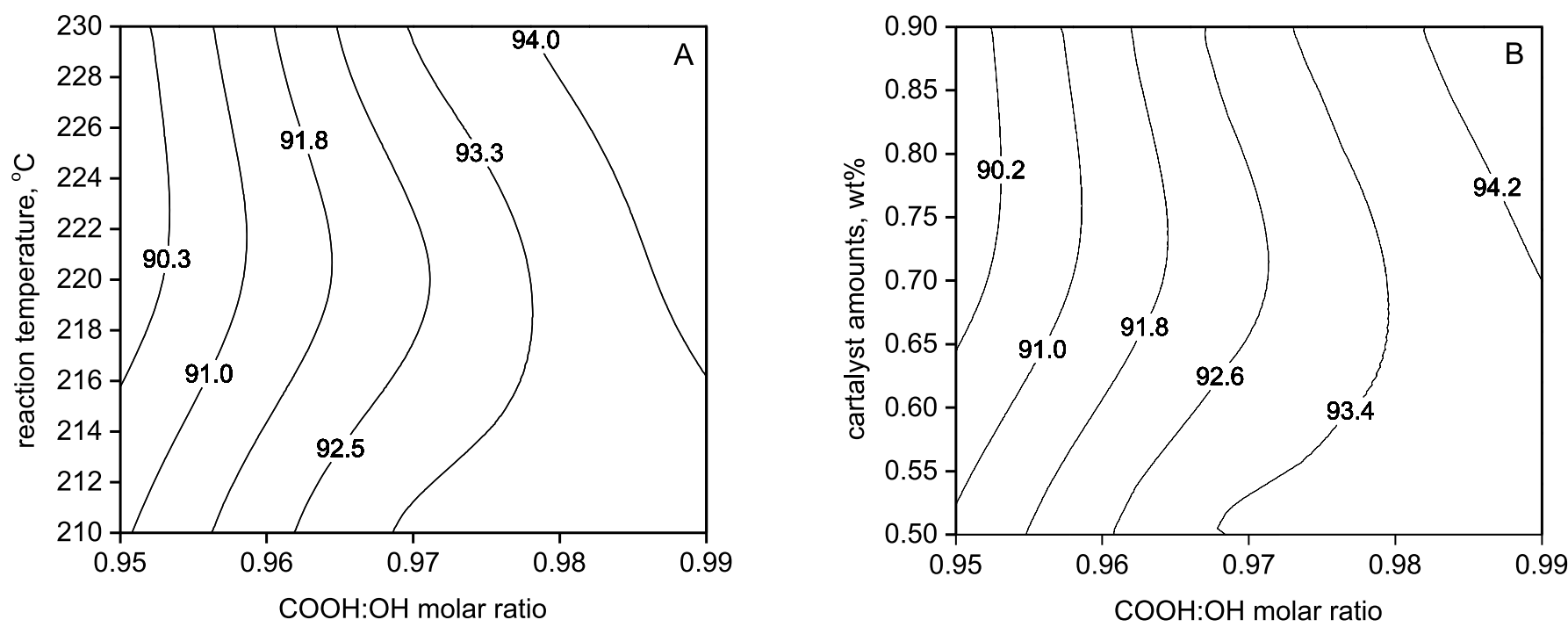

Figure 2. Conture plots for the trimethylolpropane trioleate content in post-synthesis mixtures. Change variables were (A) $\mathrm{COOH}$ : $\mathrm{OH}$ molar ratio and reaction temperature (reaction time $-6 \mathrm{hr}$; catalyst $-0.7 \mathrm{wt} \%$ ), (B) $\mathrm{COOH}:$ molar ratio and amount of catalyst (reaction time $-6 \mathrm{hr}$; reaction temperature $-220^{\circ} \mathrm{C}$ ) 
with oleic acid were: $\mathrm{COOH}: \mathrm{OH}$ molar ratio, 0.99 : 1 ; reaction temperature, $230^{\circ} \mathrm{C}$; amount of added catalyst, 0.7-0.9 wt\%. Under this reaction conditions TMP trioleate content in post-synthesis mixture above of 94 wt $\%$ was achieved.

\section{Effect of reaction parameters on TMP isostearic acid} ester synthesis

The 3D plots and 2D contout plots were developed with trimethylolpropane triester contents in post-synthesis mixtures. Figures $3 \mathrm{~A}$ and $4 \mathrm{~A}$ show the effect of $\mathrm{COOH}$ : $\mathrm{OH}$ molar ratio and reaction temperature on TMP triisostearate content in post-synthesis mixture formed in esterification reaction of oleic acid with trimethylolpropane catalysed by $\mathrm{Sn}$ bis(2-ethylhexanoate) at constant reaction time of $6 \mathrm{hr}$. The analogously to TMP trioleate the TMP triisostearate content also increased as the $\mathrm{COOH}: \mathrm{OH}$ molar ratio increased to close to equimolar. Figure 3B and 4B show the effect of $\mathrm{COOH}$ : OH molar ratio and amount of added catalyst on TMP triisostearate content in post-synthesis mixture. Similarly to TMP trioleate the TMP triisostearate content increased also as the reaction temperature increased from 210 to $230^{\circ} \mathrm{C}$. The maximum of TMP triisostearate content in post-synthesis mixture ( $>94 \mathrm{wt} \%$ ) can by obtained for the molar ratio from $0.92: 1$ to $0.94: 1$, reaction temperature from 220 to $230^{\circ} \mathrm{C}$. A similar effect was also observed in effect of $\mathrm{COOH}: \mathrm{OH}$ molar rario and amount of added catalyst. The maximum of TMP triisostearate content can be obtained for the molar ratio $0.94: 1$ and amount of added catalyst from 0.8 to 0.9 wt $\%$. (see Figure 3B and 4B).

According to the adopted model, the estimated optimum conditions for esterification of trimethylolpropane with isostearic acid were: $\mathrm{COOH}$ : $\mathrm{OH}$ molar ratio, 0.94 : 1 ; reaction temperature, $230^{\circ} \mathrm{C}$; amount of added catalyst, $0.9 \mathrm{wt} \%$. Under this reaction conditions TMP triisostearate content in post-synthesis mixture above of $94 \mathrm{wt} \%$ was achieved.

\section{Physicochemical characteristics of TMP fatty acid esters}

Under the optimal reaction conditions the synthesis of oleic acid and isosteraric acid esters of trimethylolpropane were performed. The crude TMP ester was washed with
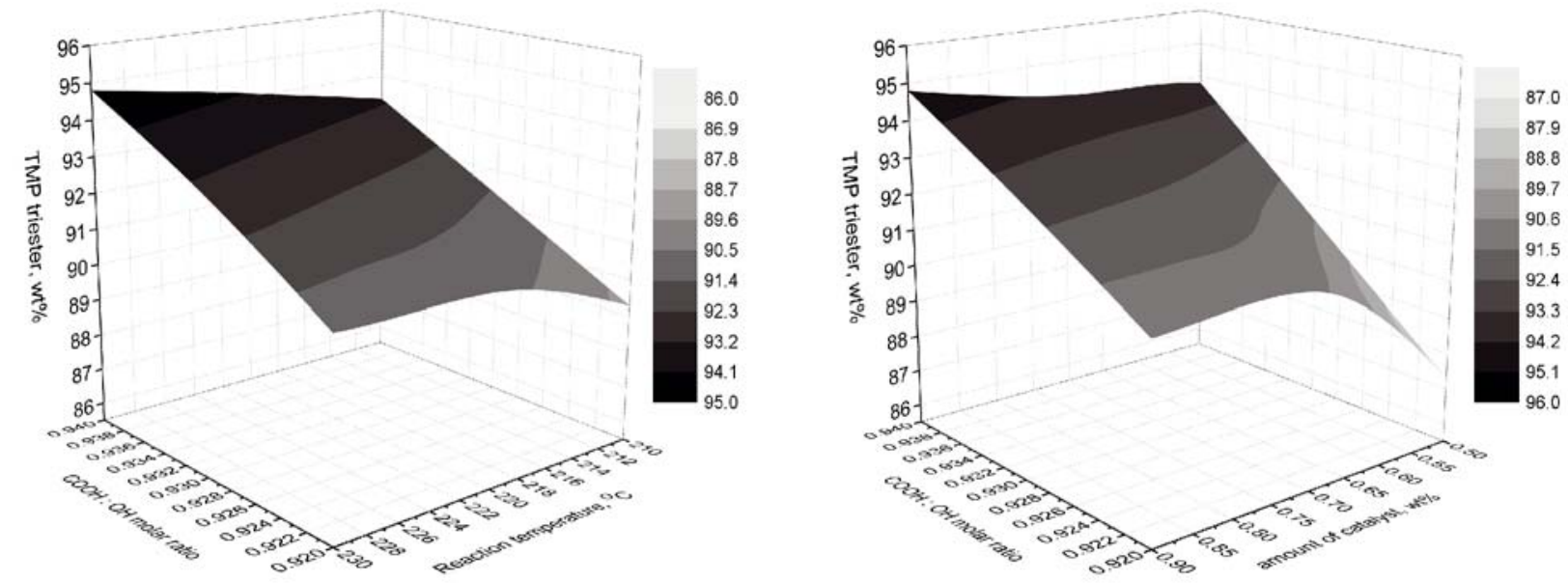

Figure 3. 3D surface plots for the trimethylolpropane triisostearate content in post-synthesis mixtures. Change variables were (A) $\mathrm{COOH}: \mathrm{OH}$ molar ratio and reaction temperature (reaction time $-6 \mathrm{hr}$; catalyst $-0.7 \mathrm{wt} \%)$, (B) $\mathrm{COOH}:$ molar ratio and amount of catalyst (reaction time $-6 \mathrm{hr}$; reaction temperature $-220^{\circ} \mathrm{C}$ )
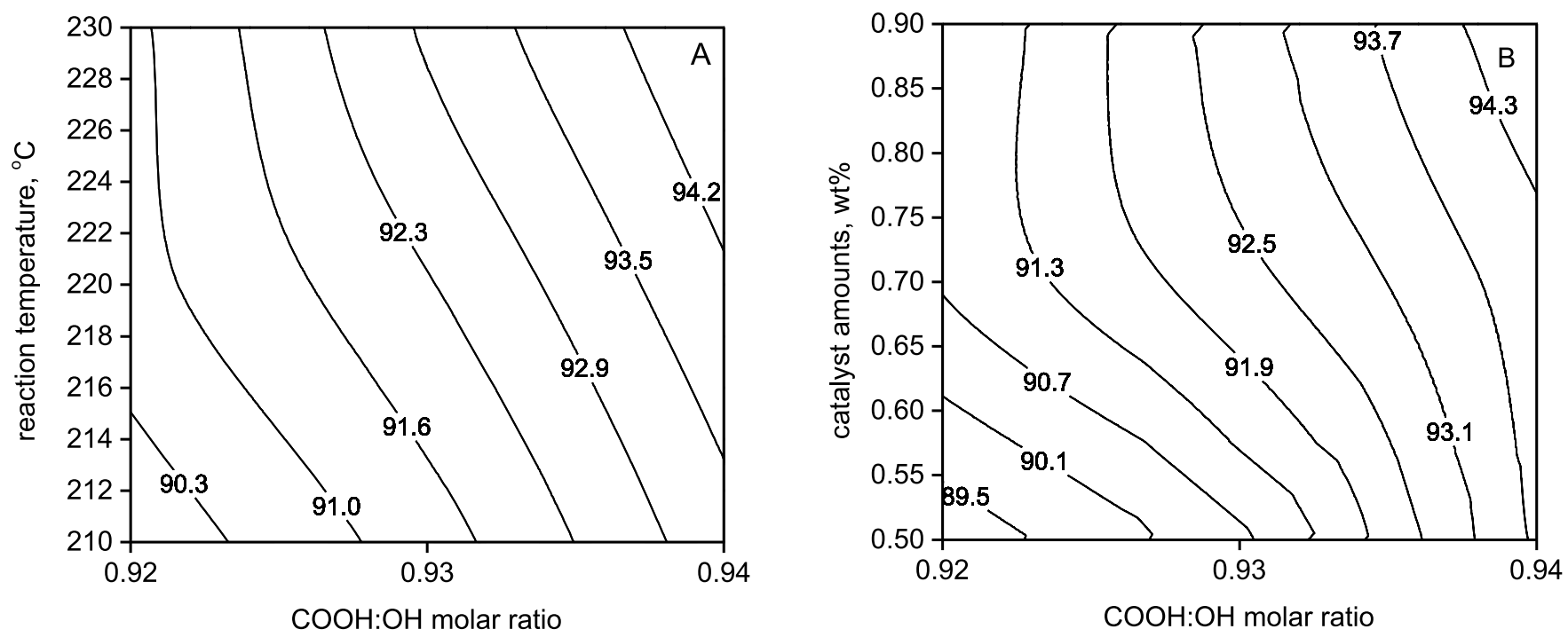

Figure 4. Surface plots for the trimethylolpropane triisostearate mixtures. Change variables were $(\mathrm{A}) \mathrm{COOH}: \mathrm{OH}$ molar ratio and reaction temperature (reaction time $-6 \mathrm{hr}$; catalyst $-0.7 \mathrm{wt} \%$ ), (B) $\mathrm{COOH}$ : molar ratio and amount of catalyst (reaction time $-6 \mathrm{hr}$; reaction temperature $-220^{\circ} \mathrm{C}$ ) 
the use of $5 \mathrm{wt} \%$ water solution of $\mathrm{K}_{3} \mathrm{PO}_{4}(10 \mathrm{wt} \%$ in relation to crude ester). The amount of $\mathrm{K}_{3} \mathrm{PO}_{4}$ used for washing was calculated as a three-fold molar excess relative to the acid number of the crude product. The purification washing was performed at $50^{\circ} \mathrm{C}$ for $30 \mathrm{~min}$. After phase separation, the ester was washed twice with water to neutral $\mathrm{pH}$ and finally dried under reduced pressure. Table 6 summarizes the compositions of the purified TMP oleic and isostearic acid esters.

Table 6. Compositions of purified trimethylolpropane ester of oleic and isostearic acid (GC, wt\%)

\begin{tabular}{|l|c|c|}
\hline Fatty acid & oleic acid & isostearic acid \\
\hline TMP & - & - \\
\hline FA & 0.2 & 0.2 \\
\hline Monoesters & 0.4 & 0.9 \\
\hline Diesters & 3.0 & 4.0 \\
\hline Triesters & 95.7 & 94.1 \\
\hline Other & 0.7 & 0.8 \\
\hline$\Sigma$ di- and triesters & 98.7 & 98.1 \\
\hline
\end{tabular}

The composition of the purified TMP oleate obtained in this study was significantly better than commercially available TMP oleate. The content of oleic acid triester was $95.7 \mathrm{wt} \%$ and sum of di- and tresters was $98.7 \mathrm{wt} \%$. The composition of TMP isostearate was similar to the corresponding ester of oleic acid. The content of triester was $94.1 \mathrm{wt} \%$ and the content of the sum of di- and tresters was $98.1 \mathrm{wt} \%$.

In Figure 5 and 6 FTIR spectra of both TMP esters are presented.

FTIR spectroscopy confirms the high purity of synthesized esters. In particular, the appearance and intensity of absorption peaks corresponding to the stretching vibration of $\mathrm{C}=\mathrm{O}$ of carboxylic ester groups at around 1730-1745 $\mathrm{cm}^{-1}$ and $\mathrm{OH}$ hydroxyl polyol groups at $3440-3480 \mathrm{~cm}^{-1}$. The formation of carboxylic ester can be also confirmed by appearance of the peaks assigned to ester $\mathrm{C}-\mathrm{O}$ stretching band at ca. $1150 \mathrm{~cm}^{-1}$ and ester $\mathrm{C}=\mathrm{O}$ band at ca. $1740 \mathrm{~cm}^{-1}$. Moreover, the disappearance of peak corresponding to the stretching of polyols $\mathrm{O}-\mathrm{H}$ groups at ca. $3460 \mathrm{~cm}^{-1}$ has also confirmed the formation of esters. All FTIR spectra recorded for synthesized esters show the appearance of characteristic ester peaks (1162 and $1740 \mathrm{~cm}^{-1}$ ) and peaks assigned to hydroxyl O-H groups which are significantly reduced.

For the obtained esters of oleic acid, the basic physicochemical properties were determined including viscosity characteristics, viscosity index, acid number and pour point. The results were compared with the values of the corresponding parameters for a commercial grade TMP oleic acid and isostearic acid esters (Table 7).

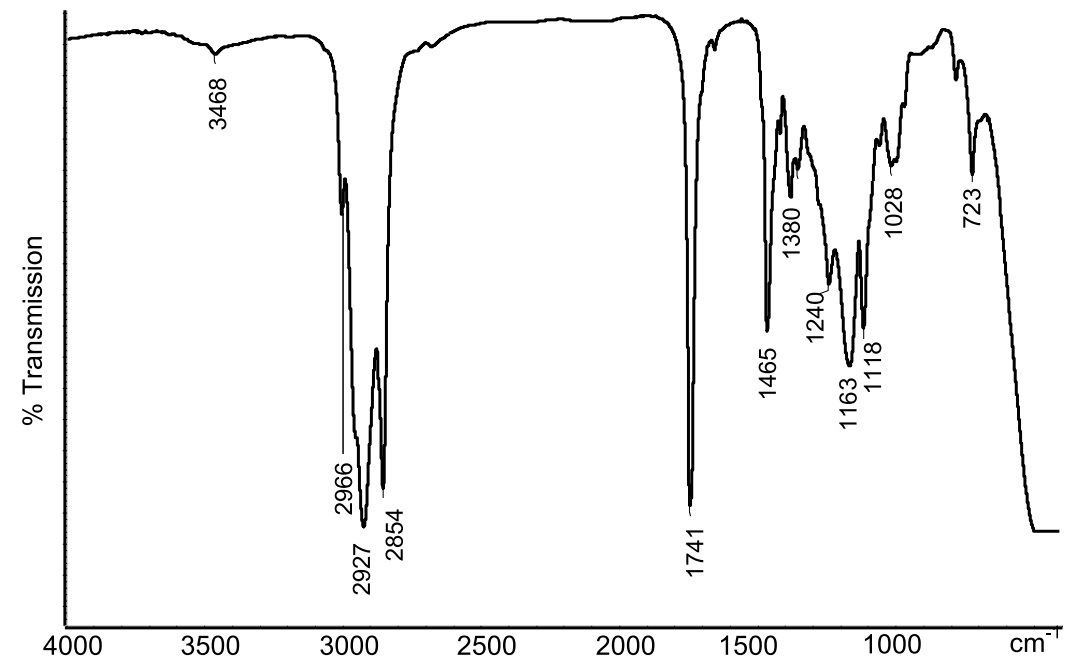

Figure 5. FTIR spectrum of trimethylolpropane trioleate

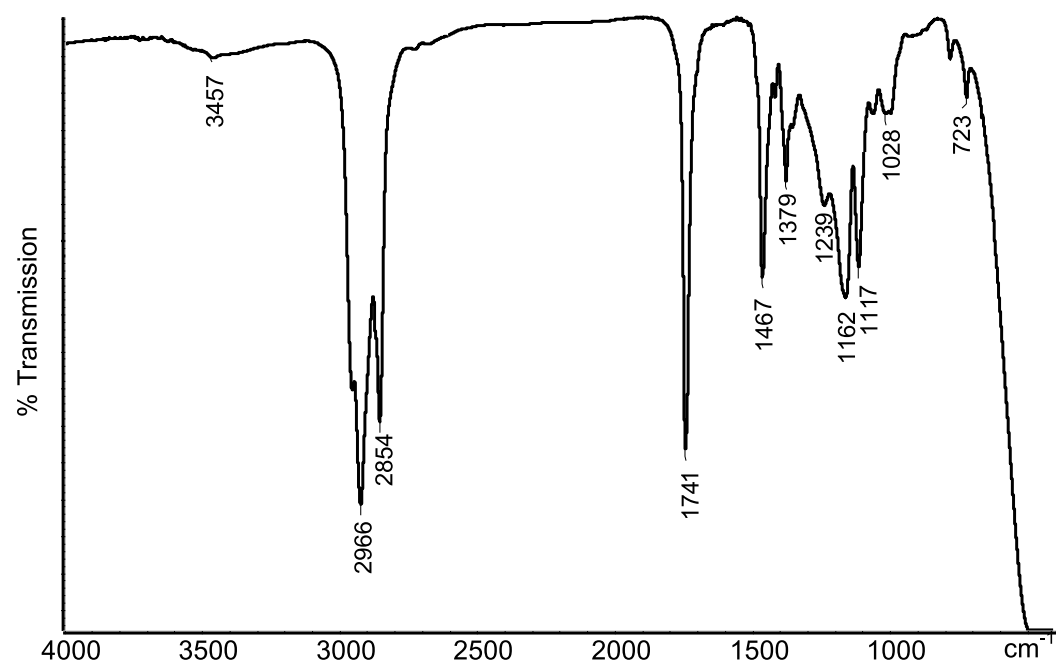

Figure 6. FTIR spectrum of trimethylolpropane triisostearate 
Table 7. Physicochemical characteristics of oleic and isostearic acid esters of TMP

\begin{tabular}{|c|c|c|c|c|}
\hline Product & $\begin{array}{l}\text { TMP trioleate comm. } \\
\text { grade }^{1)}\end{array}$ & TMP oleate & $\begin{array}{c}\text { TMP isostearate comm. } \\
\text { grade }^{2)}\end{array}$ & TMP isostearate \\
\hline Appearance & yellowish, clear liquid & $\begin{array}{c}\text { yellowish, clear } \\
\text { liquid }\end{array}$ & colorless, clear liquid & $\begin{array}{c}\text { colorless, clear } \\
\text { liquid }\end{array}$ \\
\hline Color (Gardner) & 5 & 5 & $2-5$ & 3 \\
\hline $\begin{array}{c}\text { Viscosity, } \mathrm{m}^{2} / \mathrm{s} \\
40^{\circ} \mathrm{C} \\
100^{\circ} \mathrm{C}\end{array}$ & $\begin{array}{l}47 \\
9.8\end{array}$ & $\begin{array}{l}47 \\
9.8\end{array}$ & $\begin{array}{l}90 \\
14\end{array}$ & $\begin{array}{l}92 \\
15\end{array}$ \\
\hline Viscosity index & 185 & 185 & 144 & 157 \\
\hline $\mathrm{L}_{\mathrm{A}}, \mathrm{mg} \mathrm{KOH} / \mathrm{g}$ & 0.5 & 0.2 & 0.2 & 0.2 \\
\hline $\mathrm{L}_{\mathrm{s}}, \mathrm{mg} \mathrm{KOH} / \mathrm{g}$ & 175 & 175 & 172 & 175 \\
\hline $\mathrm{L}_{\mathrm{OH}}, \mathrm{mg} \mathrm{KOH} / \mathrm{g}$ & $\leq 10$ & 7 & 13 & 9 \\
\hline Pour point, ${ }^{\circ} \mathrm{C}$ & -51 & $<-55$ & -26 & -26 \\
\hline
\end{tabular}

$\mathrm{LA}$ - acid value; LS - saponification value; $\mathrm{LOH}$ - hydroxyl value;

$1,2)$ Industrial Quimica Lasem Technical Data (Spain)

The results summarized in Table 7 show, that trimethylolpropane trioleate obtained with the use of homogeneous organotin catalyst is characterized by similar physicochemical data compared to commercial trimethylolpropane trioleate. However, commercial TMP ester is manufactured by using a more onerous technology, that requires purification distillation under very high vacuum. The new and convenient method described in this paper is free of this problem. Lower hydroxyl value proves also, that the use of Sn bis(2-ethylhexanoate) as catalyst leads to a product having a lower content of undesirable TMP mono- and diesters.

Table 6 presented also the chemical composition of purified TMP isostearic acid ester. In our studies we used isostearic acid obtained from oleic acid, so it can also be considered as a raw material derived from renewable sources. Both oleic and isostearic acid esters of trimethylolpropane are used as lubricants for hydraulic and metalworking oils, plastics, textiles; in the cosmetic industry as emollients and also as replacements for petroleum-based lubricants in metalworking ${ }^{36}$. The chemical compositions of isostearic acid esters shown in Table 8 does not significantly differ from the corresponding of oleic acid esters. Table 7 presents the results of determinations of physicochemical properties of isostearic acid esters. TMP isostearic acid ester is characterized by significantly higher kinematic viscosity values, but also by lower, compared to the corresponding oleic acid ester, values of the viscosity index (V.I.). Obtained TMP isostearic acid ester is also characterized by lower, compared to commercial product, hydroxyl value.

\section{Tribological characteristics of TMP fatty acid esters}

The results of the performed four-ball test of obtained esters show that esters of fatty acids (oleic and isostearic) and TMP synthetized according to the adopted method, which used easily accessible homogeneous organotin catalyst, are characterized by good lubrication properties. The results of four-ball test of synthesized esters were presented in Table 8.

Table 8. Tribological properties of trimethylolpropane fatty acid esters

\begin{tabular}{|l|c|c|}
\hline & $\begin{array}{c}\text { TMP } \\
\text { oleate }\end{array}$ & $\begin{array}{c}\text { TMP } \\
\text { isostearate }\end{array}$ \\
\hline Wear scar d, $\mathrm{mm}$ & 0.73 & 0.71 \\
\hline Limit. wear load, $\mathrm{G}_{\mathrm{oz}}, \mathrm{N} / \mathrm{mm}^{2}$ & 382.9 & 404,8 \\
\hline Scuffing load, $\mathrm{P}_{\mathrm{t}, \mathrm{N}}$ & 1850 & 1300 \\
\hline $\begin{array}{l}\text { Limit. pressure of seizure, } \mathrm{p}_{\mathrm{oz}}, \\
\mathrm{N} / \mathrm{mm}^{2}\end{array}$ & 355.5 & 318.1 \\
\hline
\end{tabular}

Measured scuffing load of esters were at the level of $1850-1300 \mathrm{~N}$ and wear scar diameter of 0.73 and 0.71 $\mathrm{mm}$ respectively can be considered as good and similar to published data for pentaerythritol oleate $(1600 \mathrm{~N}$ and $0.79 \mathrm{~mm}$ respectively), in particular wear scar diameter ${ }^{22}$. As can be seen in Table 10 lubrication properties of TMP isostearic ester are significantly better compared to the corresponding oleic acid esters. Physicochemical and tribological properties of TMP esters indicated in Tables 9 and 10 clearly show that the described method for the synthesis of polyol esters using the specific homogeneous organotin catalyst provides a convenient way to obtain products which are potentially useful for tribological and cosmetic applications.

\section{CONCLUSIONS}

The esterification of trimethylolpropane with oleic acid and vegetable-derived isostearic acid was carried out using homogenous organometallic catalysts - Sn bis(2-ethylhexanoate). For this catalyst the optimal synthesis parameters were determined, in particular, the fatty acid-polyol molar ratio, the reaction temperature, the reaction time and the amount of added catalyst. Based on the preliminary studies on the synthesis of fatty acid esters of polyols we have adopted 6 hours as an effective reaction time and three other reaction parameters were further optimized. The optimization studies were conducted according to 3-level 3-factor plan of experiments based on Box-Behnken statistical methodology. Under the adopted reaction conditions the highest conversion of fatty acid, close to $99 \%$ was achieved and additionally the sum of di- and triesters in post-synthesis mixtures was above $98 \mathrm{wt} \%$, significantly better compared to commercial available TMP ester without deep vacuum purifying distillation. The described method of the synthesis is suitable for industrial scale and allows to obtain high-quality products fully suitable for many technical applications. A systematic evaluation of basic physicochemical and lubricating properties of the synthesized esters was also carried out and their good properties as biolubricants were confirmed. 


\section{SUPPORTING INFORMATIONS}

Table S1. Independent variables and their levels used in the experimental design for trimethylolpropane oleic acid ester synthesis

\begin{tabular}{|c|c|c|c|}
\hline Level & $X_{1}$ & $X_{2}$ & $X_{3}$ \\
\hline 1 & $0.99: 1$ & 230 & 0.9 \\
0 & $0.97: 1$ & 220 & 0.7 \\
-1 & $0.95: 1$ & 210 & 0.5 \\
\hline
\end{tabular}

Table S2. Design of experiments and response of TMP triester content for trimetylolopropane oleic acid ester synthesis

\begin{tabular}{|c|c|c|c|c|}
\hline Run & $\begin{array}{c}\text { molar ratio } \mathrm{COOH}: \mathrm{OH} \\
X_{1}\end{array}$ & $\begin{array}{c}\text { reaction temperature } \\
{\left[{ }^{\circ} \mathrm{C}\right] X_{2}}\end{array}$ & $\begin{array}{c}\text { catalyst amounts } \\
{[\mathrm{wt} \%] X_{3}}\end{array}$ & $\begin{array}{c}\text { TMP triester content } \\
{[\mathrm{wt} \%] Y}\end{array}$ \\
\hline 1 & $0.99: 1$ & 230 & 0.7 & 94.3 \\
\hline 2 & $0.99: 1$ & 210 & 0.7 & 93.3 \\
\hline 3 & $0.95: 1$ & 230 & 0.7 & 90.9 \\
\hline 4 & $0.95: 1$ & 220 & 0.7 & 90.8 \\
\hline 5 & $0.97: 1$ & 220 & 0.7 & 92.2 \\
\hline 6 & $0.99: 1$ & 220 & 0.9 & 94.2 \\
\hline 7 & $0.99: 1$ & 220 & 0.5 & 94.6 \\
\hline 8 & $0.95: 1$ & 220 & 0.9 & 90.8 \\
\hline 9 & $0.97: 1$ & 220 & 0.9 & 92.7 \\
\hline 10 & $0.97: 1$ & 230 & 0.9 & 93.6 \\
\hline 11 & $0.97: 1$ & 210 & 0.5 & 90.5 \\
\hline $12^{1)}$ & $0.97: 1$ & 210 & 0.5 & 90.7 \\
\hline 13 & $0.97: 1$ & 230 & 0.7 & 93 \\
\hline 14 & $0.97: 1$ & 210 & 0.9 & 9.9 \\
\hline $15^{2)}$ & $0.97: 1$ & 220 & 0.7 & 92.2 \\
\hline
\end{tabular}

$1,2)$ - repetitive runs

Table S3. Independent variables and their levels used in the experimental design for trimethylolpropane isostearic acid ester synthesis

\begin{tabular}{|c|c|c|c|}
\hline Level & $X_{1}$ & $X_{2}$ & $X_{3}$ \\
\hline 1 & $0.94: 1$ & 230 & 0.9 \\
0 & $0.93: 1$ & 220 & 0.7 \\
-1 & $0.92: 1$ & 210 & 0.5 \\
\hline
\end{tabular}

Table S4. Design of experiments and response of TMP triester content for trimetylolopropane isostearic acid ester synthesis

\begin{tabular}{|c|c|c|c|c|}
\hline & $\begin{array}{c}\text { molar ratio } \mathrm{COOH}: \mathrm{OH} \\
X_{1}\end{array}$ & $\begin{array}{c}\text { reaction temperature } \\
{\left[{ }^{\circ} \mathrm{C}\right] X_{2}}\end{array}$ & $\begin{array}{c}\text { catalyst amounts } \\
{[\mathrm{wt} \%] X_{3}}\end{array}$ & $\begin{array}{c}\text { TMP triester content } \\
{[\mathrm{wt} \%] Y}\end{array}$ \\
\hline Run & 0.94 & 230 & 0.7 & 94.8 \\
\hline 1 & 0.94 & 210 & 0.7 & 93.3 \\
\hline 3 & 0.92 & 230 & 0.7 & 90.8 \\
\hline 4 & 0.92 & 220 & 0.7 & 90.7 \\
\hline 5 & 0.93 & 220 & 0.9 & 9.9 \\
\hline 6 & 0.94 & 220 & 0.5 & 93.4 \\
\hline 7 & 0.94 & 220 & 0.9 & 90.7 \\
\hline 8 & 0.92 & 220 & 0.9 & 92.5 \\
\hline 9 & 0.93 & 220 & 0.9 & 93.2 \\
\hline 10 & 0.93 & 230 & 0.5 & 90.5 \\
\hline 11 & 0.93 & 210 & 0.5 & 90.6 \\
\hline $12^{1)}$ & 0.93 & 210 & 0.7 & 92.8 \\
\hline 13 & 0.93 & 230 & 0.9 & 91.8 \\
\hline 14 & 0.93 & 210 & 0.7 & 92.1 \\
\hline
\end{tabular}

$1,2)$ - repetitive runs

\section{ACKNOWLEDGMENTS}

This study was supported by Polish National Centre for Research and Development (NCRD), project PBS2/ B1/6/2013 LUBOILEST "Studies on the technology for producing biodegradable lubricants with improved oxidation resistance and improved low-temperature characteristic".

\section{LITERATURE CITED}

1. Erhan, S.Z. \& Asadauskas, S. (2000) Lubricant basestocks from vegetable oils. Ind. Crop. Prod. 11, 277-282. DOI: 10.1016/ S0926-6690(99)00061-8.

2. Alias, N.H., Yunus, R., Idris, A. \& Omar, R. (2009) Effects of additives on oxidation characteristics of palm oil-based trimethylolpropane ester in hydraulics applications. Eur. J. Lipid Sci. Technol. 111, 368-375. DOI: 10.1002/ejlt.200800136. 
3. Pettersson, A. (2007) High-performance base fluids for environmentally adapted lubricants. Tribol. Int. 40, 638-645. DOI: 10.1016/j.triboint.2005.11.016.

4. Kiriliauskaite, V., Bendikiene, V. \& Juodka, B. (2011) Synthesis of trimethylolpropane esters of oleic acid by Lipoprime 50T. J. Ind. Microbiol. Biot. 38, 1561-1566. DOI: 10.1007/ s10295-011-0946-3.

5. Willing, A. (2001) Lubricants based on renewable resources - an environmentally compatible alternative to mineral oil products. Chemosphere 43, 89-98. DOI: 10.1016/S00456535(00)00328-3.

6. Nagendramma, P. (2011) Study of pentaerythritol tetraoleate ester as industrial gear oil Lubr. Sci. 23, 355-362. DOI: 10.1002/ls.161.

7. McNutt, J. \& He, Q. (2016) Development of biolubricants from vegetable oils via chemical modification. J. Ind. Eng. Chem. 36, 1-12. DOI: 10.1016/j.jiec.2016.02.008.

8. Syahir, A.Z., Zulkifli, N.W.M., Masjuki, H.H., Kalam, M.A., Alabdulkarem, A, Gulzar, M., Khuong, L.S. \& Harith, M.H. (2017) A review on bio-based lubricants and their applications. J. Clean. Sci. 168, 997-1016. DOI: 10.1016/j.jclepro.2017.09.106.

9. Panchal, T.M., Patel, A., Chauhan, D.D., Thomas, M. \&Pate, J.V. (2017) A methodological review on bio-lubricants from vegetable oil based resources. Renev. Sustain. Energ, Rev., 70, 65-70. DOI: 10.1016/j.rser.2016.11.105.

10. Zainal, N.A., Zulkifli, N.W.M., Gulzar, M. \& Masjuki, H.H. (2018) A review on the chemistry, production, and technological potential of bio-based lubricants. Renev. Sustain. Energ, Rev., 82, 80-102.

11. Bongardt, F., Bossmann, B., Westfechtel, A. \& Giede, W. (1996) Synthetische ester aus alkoholen und fettsäuregemischen aus ölsäurereichen, stearinsäurearmen pflanzenölen. German Pat. DE 4444137.

12. Lämsä, M. (1996) Process for preparing a synthetic ester from a vegetable oil. World Pat. WO 1996007632 A1.

13. Leleu, G., Bédague, P. \& Silion, S. (1977) Trimethylolpropane esters useful as base lubricants for motor oils. USA Pat. US 4061581.

14. Tsai, M, Laemmle JT (1987) Metalworking with a trimethylolalkane ester lubricant. USA Pat US 4655947.

15. Mattei, L., Pacor, P. \& Piccone, A. (1995) Oils with Low Environmental Impact for Modern Combustion Engines. Synth. Lubr. 26,49-52. DOI: 10.1007/s11746-998-0094-8.

16. Lawate, S.S. \& Lal, L. (1998) High oleic polyol esters, compositions and lubricants, functional fluids and greases containing the same. USA Pat. US 5773391.

17. Yunus, R., Fakhru'l-Razi, A., Ooi, T.L., Biak, D.L. \& Iyuke, S.E. (2004) Kinetics of transesterification of palm-based methyl esters with trimethylolpropane. J. Am. Oil Chem. Soc. 81, 497-503. DOI: 10.1007/s11746-004-0930-7.

18. Uosukainen, E., Linko, Y.Y., Lämsä, M., Tervakangas, T. \& Linko, P. (1998) Transesterification of trimethylolpropane and rapeseed oil methyl ester to environmentally acceptable lubricants. J. Am. Oil Chem. Soc. 75, 1557-1563. DOI: 10.1007/ s11746-998-0094-8.

19. Wang, E., Ma, X., Tang, Sh., Yan, R., Wang, Y., Riley, W.W. \& Reaney, M.J.T. (2014) Synthesis and oxidative stability of trimethylolpropane fatty acid triester as a biolubricant base oil from waste cooking oil. Biomass Bioenerg. 66, 371-378, DOI: 10.1016/j.biombioe.2014.03.022.

20. Chang, T., Yunus, R., Rashid, U., Choong, T. S.Y., Biak, D.R.A. \& Syam, A.M. (2015) Palm Oil Derived Trimethylolpropane Triesters Synthetic Lubricants and Usage in Industrial Metalworking Fluid. J. Oleo Sci. 64, 143-151.

21. Hamid, H.A., Yunus, R., Rashid, U., Choong, T. S.Y., Ali, S. \& Syam, A.M. (2016) Synthesis of high oleic palm oil-based trimethylolpropane esters in a vacuum operated pulsed loop reactor. Fuel, 166, 560-566.

22. Srinivas, D. \& Kotwal, M. (2013) Process for preparing biodegradable lubricant base oils World Pat. WO 2013175509.
23. Brini, S., Psaro, R., Zaccheria, F. \& Ravasio, M.N. (2014) Process or the synthesis of esters of fatty acids in the presence of catalyst. World Pat. WO 201400659.

24. Zaccheria, F., Mariani, M., Psaro, R., Bondioli, P. \& Ravasio, N. (2016) Environmentally friendly lubricants through a zero waste process. Appl. Catal. B: Environ. 181, 581-586. DOI: 10.1016/j.apcatb.2015.08.032.

25. Kotwal, M., Kumar, A. \& Darbha, S. (2013) Three-dimensional, mesoporous titanosilicates as catalysts for producing biodiesel and biolubricants. J. Mol. Catal. A, Chemical 377, 65-73. DOI: 10.1016/j.molcata.2013.04.029.

26. Varhadi, P., Kotwal, M. \& Srinivas, D. (2013) Zirconium phenyl phosphonate phosphite as a highly active, reusable, solid acid catalyst for producing fatty acid polyol. Appl. Catal. A: General 462-463, 129-136. DOI: 10.1016/j.apcata.2013.04.043.

27. Oh, J., Yang, S., Kim, Ch., Choi, I., Kim, J. \& Lee, H. (2013) Synthesis of biolubricants using sulfated zirconia catalysts. Appl Catal A: General 455, 164-171. DOI: 10.1016/j. apcata.2013.01.032.

28. Nagendramma, P., Kaul, S. \& Bisht, R.P.S. (2010) Study of synthesized ecofriendly and biodegradable esters: fire resistance and lubricating properties. Lubr. Sci. 22,103-110. DOI: $10.1002 / \mathrm{ls} .108$.

29. Linko, Y.Y., Tervakangas, T., Lamsa, M. \& Linko, P. (1997) Production of trimethylolpropane esters of rapeseed oil fatty acids by immobilized lipase. Biotechnol. Tech . 11, 889-892. DOI: $10.1023 / \mathrm{A}: 1018410316231$.

30. Åkerman, C.O., Gaber, Y., Ghanid, N.A., Lämsäe, M. \& Hatti-Kaul, R. (2011) Clean synthesis of biolubricants for low temperature applications using heterogeneous catalysts. J. Mol. Catal. B. Enzym. 72 263-269. DOI: 10.1016/j.molcatb.2011.06.014.

31. Åkerman ,C.O., Hagström, A.E.V., Mollaahmad, M.A., Karlsson, S. \& Hatti-Kaul, R. (2011) Biolubricant synthesis using immobilised lipase: Process optimization of trimethylolpropane oleate production. Process. Biochem. 46, 2225-2231. DOI: 10.1016/j.procbio.2011.08.006.

32. Bongardt, F., Bossmann, B., Westfechtel, A. \& Giede, W. (1996) Synthetische Ester aus Alkoholen und Fettsäuregemischen aus ölsäurereichen, stearinsäurearmen Pflanzenölen. German Pat. DE 4444137.

33. Dai, J., Li, D., Zhao, Y. \& Xiu, Zh. (2014) Statistical Optimization for Biodiesel Production from Soybean Oil in a Microchannel Reactor. Ind. Eng. Chem. Res. 53 9325-9330. DOI: DOI: 10.1021/ie4037005.

34. El-Gendy, N.S., Deriase, S.F. \& Hamdy, A. (2014) Statistical optimization of biodiesel production from sunflower waste cooking oil using basic heterogeneous biocatalyst prepared from eggshells. Egypt J. Petrol. 24, 37-48. DOI: 10.1016/j. ejpe.2015.02.004.

35. Nowicki, J., Stańczyk, D., Drabik, J., Mosio-Mosiewski, J., Woszczyński, P. \& Warzała, M. (2016) Synthesis of Fatty Acid Esters of Selected Higher Polyols Over Homogeneous Metallic Catalysts. J. Am. Oil Chem. Soc. 93, 973-981. DOI: 10.1007/s11746-016-2840-7.

36. Ash, M. \& Ash, I. (2004) Handbook of Green Chemicals, Endicott NY, USA: Synapse Info Resources Inc., 